\title{
Advances in Forest Robotics: A State-of-the-Art Survey
}

\author{
Luiz F. P. Oliveira ${ }^{1}\left(\mathbb{D}\right.$, António P. Moreira ${ }^{1,2} \mathbb{D}$ and Manuel F. Silva ${ }^{1,3, * \mathbb{D}}$ \\ 1 Centre for Robotics in Industry and Intelligent Systems (CRIIS), INESC TEC, Rua Dr. Roberto Frias, \\ 4200-465 Porto, Portugal; luizoliveira@ieee.org (L.F.P.O.); antonio.p.moreira@inesctec.pt (A.P.M.) \\ 2 Department of Electrical and Computer Engineering, Faculty of Engineering, University of Porto, \\ Rua Dr. Roberto Frias, s/n, 4200-465 Porto, Portugal \\ 3 Department of Electrical Engineering, School of Engineering, Polytechnic of Porto, Rua Dr. António \\ Bernardino de Almeida, 431, 4249-015 Porto, Portugal \\ * Correspondence: mss@isep.ipp.pt
}

Citation: Oliveira, L.F.P.;

Moreira, A.P.; Silva, M.F. Advances in Forest Robotics: A State-of-the-Art

Survey. Robotics 2021, 10, 53.

https://doi.org/10.3390/

robotics 10020053

Academic Editor: Giulio Reina

Received: 11 February 2021

Accepted: 21 March 2021

Published: 24 March 2021

Publisher's Note: MDPI stays neutral with regard to jurisdictional claims in published maps and institutional affiliations.

Copyright: (c) 2021 by the authors. Licensee MDPI, Basel, Switzerland. This article is an open access article distributed under the terms and conditions of the Creative Commons Attribution (CC BY) license (https:/ / creativecommons.org/licenses/by/ $4.0 /)$.

\begin{abstract}
The development of robotic systems to operate in forest environments is of great relevance for the public and private sectors. In this sense, this article reviews several scientific papers, research projects and commercial products related to robotic applications for environmental preservation, monitoring, wildfire firefighting, inventory operations, planting, pruning and harvesting. After conducting critical analysis, the main characteristics observed were: (a) the locomotion system is directly affected by the type of environmental monitoring to be performed; (b) different reasons for pruning result in different locomotion and cutting systems; (c) each type of forest, in each season and each type of soil can directly interfere with the navigation technique used; and (d) the integration of the concept of swarm of robots with robots of different types of locomotion systems (land, air or sea) can compensate for the time of executing tasks in unstructured environments. Two major areas are proposed for future research works: Internet of Things (IoT)-based smart forest and navigation systems. It is expected that, with the various characteristics exposed in this paper, the current robotic forest systems will be improved, so that forest exploitation becomes more efficient and sustainable.
\end{abstract}

Keywords: forest 4.0; forest robotics; forest navigation

\section{Introduction}

Forest environments are part of the daily lives of many people around the world. According to the Food and Agriculture Organization (FAO), forests have about 4.06 billion hectares, an area equivalent to $31 \%$ of the global land area, generating around 86 million green jobs and, of the people living in extreme poverty, more than $90 \%$ depend on forests for at least part of their livelihoods such as food, fodder, shelter, energy and medicine [1]. In addition, according to the FAO, there are about 391,000 species of plants, 5000 amphibian species, 7500 bird species and more than 3700 different mammals. The formal forest market generates an income of more than $\$ 580$ billion per year when considering direct, indirect and induced employment [2]. These numbers represent not only the richness of forest regions in fauna and flora but also their great economic potential, capable of generating employment and income. The global urbanization process is transforming the means of production and labor, not only farmers, but also forestry workers, biologists and environmentalists. The relevant problem generated by accelerated urbanization is the lack of control, monitoring and preservation of forest regions, generating conflicts between loggers and indigenous people, deforestation [3], burning (being that, between 2019 and 2020, about 5.8 million hectares of temperate forest in Australia were burned [4]) and extinction of species of fauna and flora (butterfly coloration affected by forest deforestation activities [5]). According to CRED [6], between 1998 and 2017, about 3.5\% of global disasters were related to wildfires, affecting the lives of 6.2 million people, with 2398 deaths, in addition to causing economic losses of $\$ 68$ billion. 
To overcome the aforementioned challenges and improve the execution of the various forestry tasks, the concept of Forest 4.0 emerges, as shown in Figure 1.

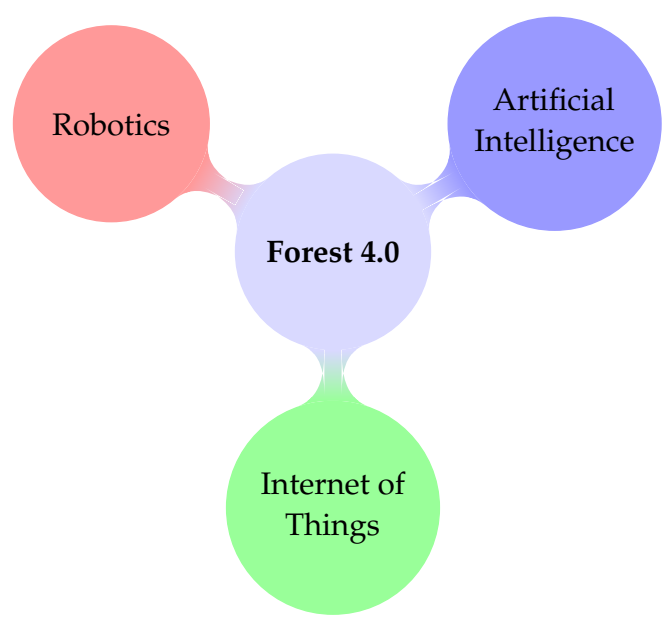

Figure 1. Forest 4.0 composition model.

As shown in Figure 1, the Forest 4.0 concept is similar to the Smart Cities concept $[7,8]$. Forest 4.0 has gained prominence with the use of robotic systems and electronic devices in forestry tasks such as environmental monitoring, fire prevention, inventory, planting, pruning and harvesting [9].

\section{Materials and Methods}

The entire process of selection of works and/or projects of robotic systems applied in performing forestry tasks was based on the most recurrent themes found in the main works and/or projects around the world. The following data platforms were used as search methods for scientific information: Google Scholar, Science Direct, IEEE Xplorer, Wiley, SpringerLink and Web of Science. Thus, scientific content was prioritized, such as articles published in journals and conferences. However, in the case of robotic systems that are already in the commercial phase, the search for elements of a technical nature took place on their respective commercial sites. At the end of the information search process, about 37 works / projects of robotic systems applied in the forest area were counted.

This review article is focused on the latest developments in forest robotic systems; however, previous works of great relevance are also described, such as the MECANT robot developed in the 1990s (described in Section 3.4). Unlike agricultural robots, which have hundreds of applications developed around the world, there are a small number of forest robot applications. This reduced number of applications can be understood by the fact that the forest environment is generally more complex than an agricultural environment, which makes it difficult to develop robust robotic systems due to variations in temperature, humidity and strongly unstructured and steep slope terrains. Since there is no pre-installed communication network infrastructure, remote communication routines are strongly impacted by the excessive number of trees acting as obstacles between the robot and the supervisor agent. Soils with a high content of stony elements, usually loose, with obstacles and/or cavities, can cause the robot to slip and/or cloak. Another difficulty found in the development of forest robots is that, unlike agricultural robots that have barns and/or human shelters to protect themselves in stormy situations, forest robots, in addition to needing specific communication and locomotion systems to operate in these environments, need to be able to remain in full operation even after an eventual storm. Although we are in 2021, there is still a high financial cost to develop robust multitasking robotic systems, making major technological developments focus only on great research and development centers. In this sense, although there are more works of forest robots, it is at a very low level of development so that works involving the use of didactic kits and/or robots that do not have practical applications of the concept were discarded. 


\section{Robotic Applications in Forest}

Robotic applications in the forestry area are divided into the following subsections: environmental preservation and monitoring; wildfire firefighting; inventory operations; and forest planting, pruning and harvesting. Therefore, the following sections address the various types of robotic system applications in forest environments individually.

\subsection{Robotic Applications for Environmental Preservation and Monitoring of Forests}

Designed to operate in the interior of the Amazon, the Environmental Hybrid Robot (EHR) Chico Mendes is a remotely operated vehicle developed to carry out monitoring missions for the Brazilian Oil Company Petrobras S.A. between the cities of Coari and Manaus, that is, about $400 \mathrm{~km}$ of gas pipeline along the forest. Chico Mendes is a wheellegged amphibious robot with active reconfiguration, capable of walking on gas pipelines, land, water, swamps and sand, as shown in Figure 2a. To control the robot's distance from the ground along with its orientation, the distance to the ground along with its gradient stability margin and traction indices, the robot has an optimal multi-objective control approach. With this approach, the robot increased the maximum tilt angle from $35^{\circ}$ to $44.8^{\circ}$, an improvement of $28 \%$. The robot also has a robotic arm with sensors for water quality and gas, Red, Green and Blue (RGB) camera and sampling support located on the final actuator, to monitor possible gas leaks and water pollution, in addition to checking out dengue outbreaks $[10,11]$.

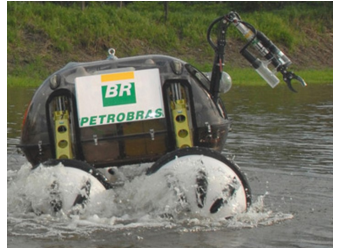

(a)

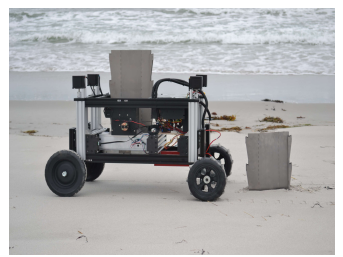

(e)

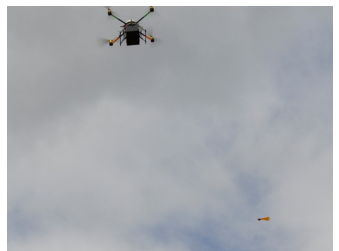

(i)

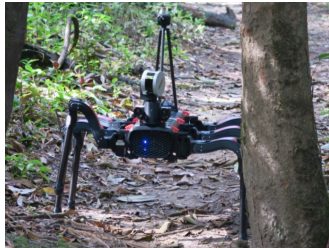

(b)

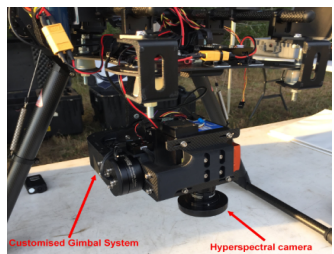

(f)

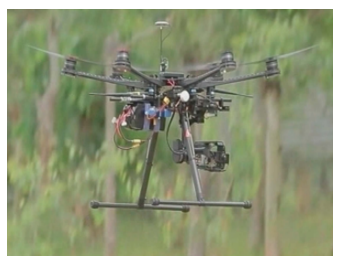

(j)

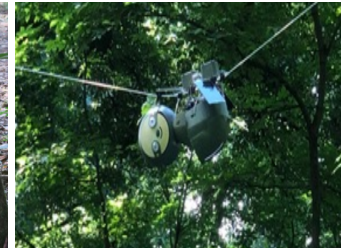

(c)

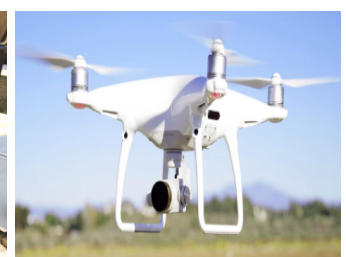

$(\mathrm{g})$

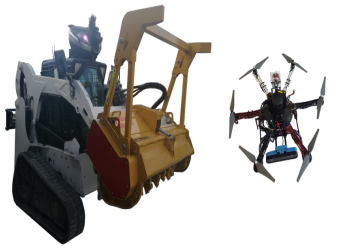

(d)

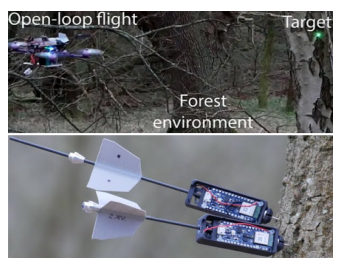

(h)

Figure 2. Examples of robotic applications used for environmental preservation and monitoring tasks in forests: (a) Chico Mendes [10], (b) Legged robot [12], (c) SlothBot [13], (d) Ranger and Scout [14], (e) Romu [15], (f) Unmanned Aerial Vehicle (UAV) robot 1 [16], (g) UAV robot 2 [17], (h) UAV robot 3 [18], (i) UAV robot 4 [19] and (j) UAV robot 5 [20].

In [12], a legged robot, as shown in Figure 2b, was used to carry out environmental monitoring activities in the Amazon. This type of locomotion system was adopted because the Amazon rainforest is characterized by being an unstructured and difficult to access environment: in addition to being a wild environment, it is a dangerous environment for human beings. In addition to allowing locomotion that adapts to the terrain slope, the 
robot is equipped with a Light Detection And Ranging (LiDAR) that maps the environment around it to perform autonomous navigation through the Simultaneous Localization and Mapping (SLAM) algorithm. The robot is part of the Providence project, sponsored by the Mamirauá Institute, which, in addition to the robot, develops several intelligent environmental monitoring devices that communicate through a wireless sensors network.

Eliminating the high irregularities of the soil and the dependence on wind conditions, the SlothBot robot makes its locomotion along wires trapped between the trees, as shown in Figure 2c. As a direct advantage, the system allows long-term environmental monitoring through low energy consumption. Through a mesh of planar wires, connecting different regions of interest, the SlothBot moves from the initial position to the desired one collecting sensory data of temperature and luminosity. It has an exclusive C-shaped mechanical system to change direction in bifurcation situations [13].

The SEMFIRE environmental preservation and forest fire prevention project was developed to reduce the accumulation of organic material in forests. Unfortunately, in the year 2020 alone, several forests suffered wild fires of extraordinary dimensions. One way to prevent the proliferation of forest fires is to reduce potential combustible materials. Thus, a multi-robot system was developed to perform the detection of regions with an accumulation of combustible material and then perform its removal. The recognition task is carried out through a swarm of Scouts, small UAV with Collective SLAM. The Scouts (Figure 2d) are looking for new Regions Of Interest (ROI) for the Ranger robot (a robot that cuts and grinds the vegetation, transforming it into mulch) to define a region of operation to perform cleaning task planning [14].

The concept of a swarm of robots was also addressed by Melenbrink and Werfel [15] who developed autonomous sheet pile driving robots for soil stabilization. To reduce hydraulic erosion activities in natural environments, they developed the Romu robot (Figure 2e) which has four wheels mounted on vertical linear actuators to assist in the task of fixing steel piles to the ground. By means of a vibratory hammer system and the reduction of the height of the robot, the system was able to fix the piles in sandy soils to a depth of $6-8 \mathrm{~cm}$. Based on a computer simulation, where several piles were fixed in sandy terrain, when simulating a stream of water going down the sandy terrain, 50\% of the soil that would be lost was retained by the barrier, indicating its great application potential [15]. Although this application is not in a forest, the challenges are similar, since the dunes environment is non-structured. In this sense, the sandy soil, the steep slope, the dust winds and changes in ambient lighting and temperature impose challenges for the development of locomotion systems, navigation algorithms and protective structures for the robot's electronic components.

Aerial mapping of forests affected by pathogens using UAV (Figure 2f), hyperspectral sensors and machine learning algorithms were studied by Sandino et al. [16]. To detect the case of myrtle rust on paperbark tea trees, they used Normalized Difference Vegetation Index (NDVI), Green Normalized Difference Vegetation Index (GNDVI), the Soil-Adjusted Vegetation Index (SAVI) and the Second Modified Adjusted Vegetation Index (MSAVI2), filtered by $2 \mathrm{D}$ smoothing kernels, in the feature extraction stage. Using the eXtreme Gradient Boosting (XGBoost) classifier, to classify the data into healthy, affected, background, soil and stems classes, the system achieved an individual detection rate of $95 \%$ for healthy trees, 97\% for deteriorated trees and 97\% for global multiclass detection [16].

Another application involving forest monitoring by UAV (Figure $2 \mathrm{~g}$ ) was described by Fujimoto et al. [17]. In this case, the methodology used by the authors was: perform individual tree detection, estimate the tree structure and simulate the carbon dynamics. The process of detecting individual trees was done by estimating the Canopy Height Model (CHM) and the extraction of individual trees was done by detecting the top of the tree and segmenting the tree canopy. The tree structure was estimated by species classification and Diameter at Breast Height (DBH) estimation. This approach achieved an individual tree detection rate of $93.4 \%$, resulting in an accuracy of $83.6 \%$ using Convolutional Neural Network (CNN) [17]. 
Forest monitoring can also be carried out by distributing Internet of Things (IoT) sensors (temperature, humidity and gas concentration sensors with a wireless communication interface) throughout the forest. The distribution of these sensors can be done by a UAV in different ways. According to Farinha et al. [18], a UAV equipped with the aerial sensor placement method based on impulsive launching, was used to launch the sensors into trees, in cluttered environments, such as under the forest canopy. The impulsive launching consists of a spring that stores the energy needed to launch the sensors to their target. In this case, the UAV (Figure 2h) was able to launch sensors to $4 \mathrm{~m}$ with an accuracy of $\pm 10 \mathrm{~cm}$. On the other hand, a UAV can be used to simply launch the sensors in a free fall. As described in [19], in order not to damage the sensor device at the time of the collision with the ground, the shape of the sensor device is inspired by Samara seeds (Figure 2i), which perform a helical movement during the free fall. Therefore, whether by the method of sensor launching or by dropping, the use of UAV is essential for displacement along the forest during the performance of forest monitoring tasks.

In [20], a UAV equipped with thermal and RGB cameras (Figure 2j) was used to carry out the monitoring and preservation activities of a group of koalas on the Sunshine Coast, Australia, as shown in Figure 3. To detect koalas through Forward-Looking InfraRed (FLIR) thermal and RGB cameras, the researchers used two distinct algorithms: Pixel Intensity Threshold (PIT) and Template Matching Binary Mask (TMBM). PIT can differentiate animals from background vegetation through the thermal signature of living beings, but it is not able to differentiate between species. To solve this problem, they developed the TMBM algorithm, which, through testing in a real scenario, was able to detect koalas in their natural environment at different altitudes $(20-30 \mathrm{~m})$ with different average detection times (1.3-1.6 s).

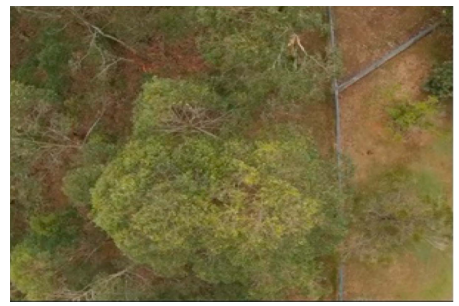

(a)

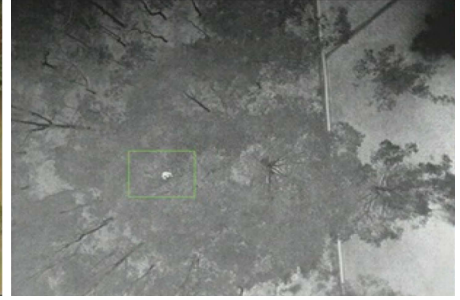

(b)

Figure 3. (a) RGB and (b) thermal images of a koala in its natural habitat captured at $60 \mathrm{~m}$ by a UAV, described in detail in [20].

Table 1 summarizes the main characteristics of the robots mentioned above.

Table 1. Comparison of the analyzed robotic applications for environmental preservation and monitoring.

\begin{tabular}{|c|c|c|c|c|}
\hline Robot & $\begin{array}{c}\text { Final } \\
\text { Application }\end{array}$ & $\begin{array}{l}\text { Locomotion } \\
\text { System }\end{array}$ & $\begin{array}{l}\text { Localization } \\
\text { Sensors }\end{array}$ & $\begin{array}{l}\text { Sensors Used to } \\
\text { Perform the Task }\end{array}$ \\
\hline Chico Mendes [10] & $\begin{array}{l}\text { Preservation and } \\
\text { monitoring }\end{array}$ & Wheel-Legged & $\begin{array}{c}\text { Global Positioning System } \\
\text { (GPS) }\end{array}$ & $\begin{array}{l}\text { Water probe, gas sensor } \\
\text { and 3D camera }\end{array}$ \\
\hline Legged robot [12] & Monitoring & Legged & $\begin{array}{l}\text { Light Detection and } \\
\text { Ranging (LiDAR) }\end{array}$ & RGB camera \\
\hline SlothBot [13] & Monitoring & Wire traversing & - & $\begin{array}{l}\text { Temperature and } \\
\text { luminosity }\end{array}$ \\
\hline Ranger and Scout [14] & $\begin{array}{l}\text { Preservation and } \\
\text { monitoring }\end{array}$ & $\begin{array}{c}\text { Caterpillar } \\
\text { and Unmanned Aerial } \\
\text { Vehicle (UAV) }\end{array}$ & $\begin{array}{c}\text { Global Navigation } \\
\text { Satellite System (GNSS) } \\
\text { and LiDAR }\end{array}$ & $\begin{array}{l}\text { Stereo, multispectral } \\
\text { and infrared cameras }\end{array}$ \\
\hline Romu [15] & Preservation & Four-wheel drive (4WD) & - & - \\
\hline UAV robot 1 [16] & Monitoring & UAV & GPS & Hyperspectral camera \\
\hline UAV robot 2 [17] & Monitoring & UAV & GPS & RGB camera \\
\hline UAV robot $3[18]$ & Monitoring & UAV & - & RGB camera \\
\hline UAV robot 4 [19] & Monitoring & UAV & - & $\begin{array}{l}\text { Temperature, humidity } \\
\text { and pressure }\end{array}$ \\
\hline UAV robot $5[20]$ & $\begin{array}{l}\text { Preservation and } \\
\text { monitoring }\end{array}$ & UAV & $\begin{array}{c}\text { GPS and Inertial } \\
\text { Measurement Unit (IMU) }\end{array}$ & Thermal and RGB cameras \\
\hline
\end{tabular}


Regarding the information presented in Table 1, the following observations can be made:

- Monitoring: The Chico Mendes robot monitors possible gas leaks in the interior of the Amazon and the SlothBot monitors the ambient temperature and luminosity. Therefore, the locomotion system is directly affected by the type of environmental monitoring to be performed.

- Swarm: Forest are unstructured environments. This characteristic directly affects the time of travel and the execution of any tasks to be performed. Therefore, the integration of the concept of swarm of robots with robots of different types of locomotion systems (land, air or sea) can compensate for the time of executing tasks in such environments.

- Artificial intelligence: Artificial intelligence was used in conjunction with robotic systems in identification processes, using natural environment characteristics (vegetation indexes) and CNN.

\subsection{Robotic Applications for Wildfire Fighting}

Unlike the monitoring of forest activities, wildfire fighting activities require direct intervention (traditionally through firefighting trucks and planes) in the forest environment so that there is a minimum of damage not only to the fauna and flora but also to the populations that live in such locations. Although forest monitoring via satellites is of paramount importance in the fight against illegal deforestation, when there are forest fires they do not contribute to the extinction of the fire. In this case, this function is entirely dependent on the replenishment of several teams of firefighters, water trucks and firefighters aircraft. The robotic applications for wildfire fighting can contribute to faster, safer and more efficient action of spraying water or retarding agents in forest regions. The design of firefighting robots has requirements such as having a mechanical structure resistant to high temperatures and concentrations of gases and dust, high payload capacity and a locomotion system designed to transport large payloads through rough terrain and be used for multitasking.

A Six-Wheel Drive (6WD) autonomous ground vehicle, developed by military product manufacturer Lockheed Martin, was adapted to perform firefighting operations. The Fire Ox robot can be integrated with an existing infrastructure or used individually, as it has a tank with a capacity of 250 gallons and an electrical generator of up to $1000 \mathrm{~W}$. This robot can be operated using a remote control and RGB and Infrared (IR) cameras [21].

Another company in the military sector, Milrem Robotics, has developed two versions of robots to firefighting operations, one to extinguish the fire and the other to assist in the transportation of hoses in hostile and difficult to access environments. Figure 4a exhibits the Multiscope Rescue with Hydra, a firefighting robot equipped with a modular foam and/or water monitor with a flow rate of $3000 \mathrm{~L} / \mathrm{min}$, which can rotate $360^{\circ}$ and disperse liquids (foam and/or water) at a distance up to $62 \mathrm{~m} \mathrm{[22].} \mathrm{The} \mathrm{robot} \mathrm{has} \mathrm{two} \mathrm{sprinklers}$ located on its front that serve as a protection system. To increase the system autonomy, the robot is powered in a hybrid way (diesel engine and battery pack) reaching a maximum autonomy of $12 \mathrm{~h}$. 


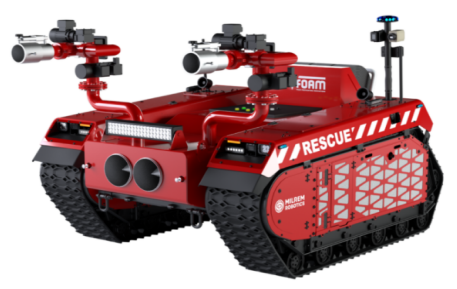

(a)

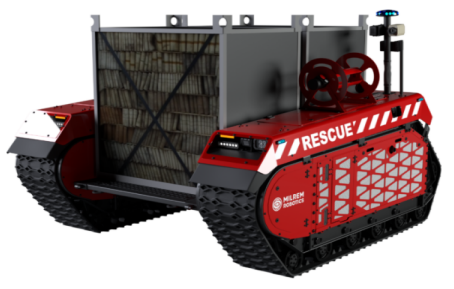

(b)

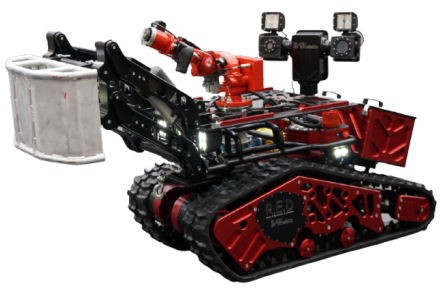

(c)

Figure 4. Examples of robotic applications used for wildfire fighting: (a) Multiscope Rescue with Hydra [22], (b) Multiscope Rescue Hose Cartridge [23] and (c) Colossus [24].

The version of the robot capable of transporting hoses, as shown in Figure $4 \mathrm{~b}$ and entitled Multiscope Rescue Hose Cartridge, has the same locomotion system as the hydra version, but it has a hose cartridge specially designed to streamline the process unloading. Through a control system by teleoperation or waypoint navigation, hoses can be quickly redirected to other locations without exposing firefighters to risky situations [23].

Unlike previous fire fighting robots, the AirCore TAF35 has a liquid jet system for nebulizing large amounts of water without using high pressure. The AirCore TAF35 includes a caterpillar system, since the unmanned vehicle weighs about $3900 \mathrm{~kg}$ and is powered by a diesel engine with $71 \mathrm{HP}$ which has a maximum autonomy of up to $7 \mathrm{~h}$. Due to its special spray system, the robot generates a sound noise of up to $84 \mathrm{~dB}$. With a speed of $9 \mathrm{~km} / \mathrm{h}$ and a maximum water flow capacity of up to $4700 \mathrm{~L} / \mathrm{min}$, this robot is capable of efficiently extinguishing large-scale wildfires. The system has a water jet that can reach a distance of up to $80 \mathrm{~m}$ and can be controlled by remote control at a distance of up to $300 \mathrm{~m}$, allowing a human operator to carry out his activities safely [25].

Thermite RS1 and Thermite RS3 robots have a water propulsion system that resembles Multiscope Rescue with Hydra and AirCore TAF35 robots, respectively. Thermite RS3 is a larger, faster version with a higher water flow than the Thermite RS1 [26]. Thermite RS3 has a Positive Pressure Ventilation (PPV) ventilator system, similar to the AirCore TAF35, capable of delivering up to $2500 \mathrm{gpm}$, about $9464 \mathrm{~L} / \mathrm{min}$.

Created in 2017 by Shark Robotics, the French robot Colossus (Figure 4c) was designed to assist the work of firefighters, not to replace them. In this sense, in addition to having a water sprayer to firefighting, the robot can be used to carry a payload of up to $500 \mathrm{~kg}$ (equipment and/or injured people/animals). The robot's chassis is made of Aluminumwelded aeronautical steel, a light and resistant material capable of withstanding thermal waves of up to $900{ }^{\circ} \mathrm{C}$, with a total weight of $500 \mathrm{~kg}$. The Colossus is capable of moving at a maximum speed of $4.5 \mathrm{~km} / \mathrm{h}$, on terrain with a slope of up to $40^{\circ}$ and overcoming obstacles of up to $30 \mathrm{~cm} \mathrm{[24].}$

Table 2 summarizes the main characteristics of the robots mentioned above.

Table 2. Comparison between the analyzed robotic applications for wildfire fighting.

\begin{tabular}{|c|c|c|c|c|c|c|c|c|}
\hline Robot & $\begin{array}{l}\text { Locomotion } \\
\text { System }\end{array}$ & $\begin{array}{l}\text { Weight } \\
\text { (kg) }\end{array}$ & $\begin{array}{c}\text { Payload } \\
\text { Weight } \\
\text { (kg) }\end{array}$ & $\begin{array}{l}\text { Water Flow } \\
\text { (L/min) }\end{array}$ & $\begin{array}{l}\text { Velocity } \\
(\mathrm{km} / \mathrm{h})\end{array}$ & $\begin{array}{l}\text { Autonomy } \\
\text { (h) }\end{array}$ & $\begin{array}{c}\text { Grade } \\
\text { Slope } \\
\left({ }^{\circ}\right)\end{array}$ & $\begin{array}{c}\text { Side } \\
\text { Slope } \\
\left({ }^{\circ}\right)\end{array}$ \\
\hline Fire Ox [21] & $\begin{array}{l}\text { Six-wheel drive } \\
\text { (6WD) }\end{array}$ & - & - & - & - & - & 30 & - \\
\hline $\begin{array}{c}\text { Multiscope Rescue } \\
\text { with Hydra [22] }\end{array}$ & Caterpillar & 1630 & 1200 & 3000 & 20 & 12 & 30 & - \\
\hline $\begin{array}{l}\text { Multiscope Rescue } \\
\text { Hose Cartridge [23] }\end{array}$ & Caterpillar & 1630 & 1200 & - & 20 & 15 & 30 & - \\
\hline $\begin{array}{l}\text { Magirus AirCore } \\
\text { TAF35 [25] }\end{array}$ & Caterpillar & 3900 & - & 4700 & 9 & 7 & 30 & 15 \\
\hline Thermite RS1 [26] & Caterpillar & 725 & - & 4732 & 9.65 & 20 & 26.57 & 19.29 \\
\hline Thermite RS3 [26] & Caterpillar & 1588 & - & 9464 & 12.87 & 20 & 26.57 & 19.29 \\
\hline Colossus [24] & Caterpillar & 500 & 500 & - & 4.5 & 12 & 40 & 35 \\
\hline
\end{tabular}


Regarding the information presented in Table 2, the following observations can be made:

- Weight and Payload: To transport more equipment and/or injured people with less environmental impact (less soil compaction), the robotic system should be light and capable of transporting large payloads. Therefore, the robot + payload set must have a low center of gravity to avoid falls during firefighting activities.

- Water Flow: To reduce the spread of fires is desirable to apply a large water flow, since water reduces the temperature existing in place, removing the existing heat of reaction, putting out the fire. Therefore, the greater is the water flow $(9464 \mathrm{~L} / \mathrm{min}$ for Thermite RS3), the faster the fire will go out and the more forest areas will be preserved.

- Velocity: Although the water flow helps the firefighting, to control large-scale fires with a limited number of robots, the faster the robot travels the more areas can be covered. In this sense, robotic systems must be agile and easy to move around in hostile and difficult to access terrains.

- Autonomy: The firefighting activity requires time to remove all the heat from the place, and, in the case of a forest fire, delays in the firefighting can mean the extinguishment of species of fauna and flora. Therefore, the greater is the autonomy of the robot, the longer is the period in which the robot will remain firefighting and, consequently, more species of fauna and flora can be saved.

- Grade and side slope: Although all the robots analyzed are capable of operating on types of surfaces commonly found in urban and rural areas, such as concrete and clay soil, each robot in Table 2 has a different maximum grade and side slope. In this sense, the higher are these values, the greater is its ability to operate in rugged environments.

\subsection{Robotic Applications in Forest for Inventory Operations}

A group of researchers assessed the performance of SLAM-aided stem mapping for forest inventory with a small-footprint mobile LiDAR. Using the FGI ROAMER R2 vehicle (Figure 5a) moving at $4 \mathrm{~km} / \mathrm{h}$, between open and dense forest regions, they compared three forms of navigation: only by Global Navigation Satellite System (GNSS), using GNSS + IMU and adopting SLAM + IMU. The proposed SLAM algorithm was the Improved Maximum Likelihood Estimation (IMLE). For the open forest regions, the SLAM algorithm was shown not to be feasible, as in this region there are few detection characteristics available and the GNSS signals have greater availability. On the other hand, in regions of dense forest, the precision of the SLAM + IMU technique was 38\% higher than the use of GNSS + IMU [27].

A location algorithm based on the LiDAR Odometry and Mapping (LOAM) in realtime approach was used in a forwarder unit (Komatsu Forest 931.1, as depicted in Figure 5b) to perform the mapping of trees during autonomous navigation in a heavy canopy forest region. The idea was to build a unique $2 \mathrm{D}$ topological graph from the map's point cloud and find an optimal relationship between the global and local topology. The detection of trunks was done by clustering the data of the point cloud for a given predetermined value. The correspondence between the local and global maps was carried out by searching for triangles based on dissimilarity and calculating pairs of corresponding vertices. As a result, the work obtained a location accuracy about $0.3 \mathrm{~m}$ with $12 \mathrm{~cm}$ of standard deviation and with the processing of data in real time for speeds of up to $0.5 \mathrm{~m} / \mathrm{s}$ [9]. 


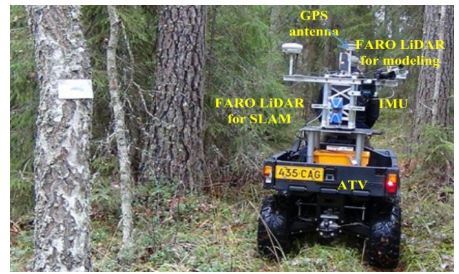

(a)

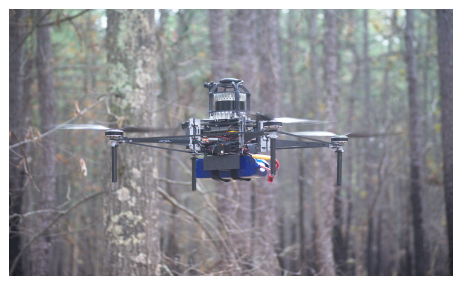

(d)

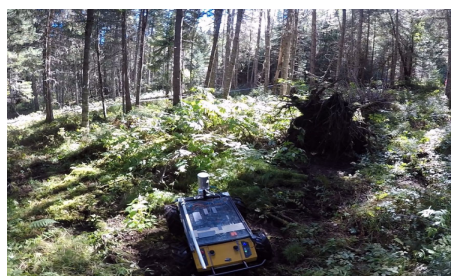

(g)

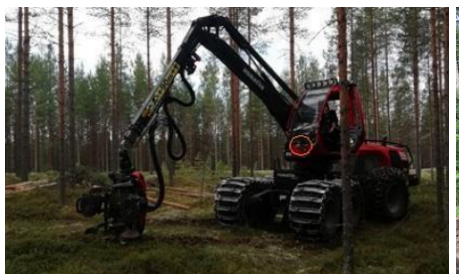

(b)

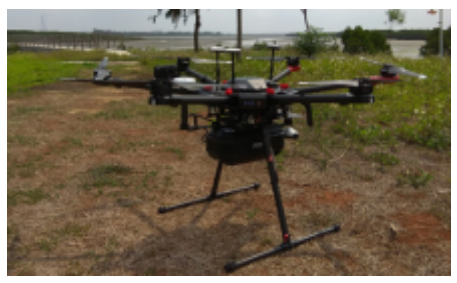

(e)

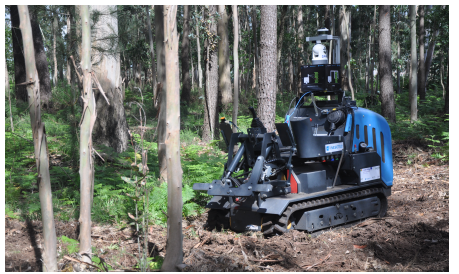

(c)

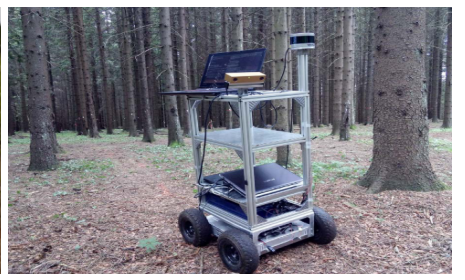

(f)

Figure 5. Examples of robotic applications used in forests for inventory operations: (a) FGI ROAMER R2 [27], (b) Komatsu Forest 931.1 [9], (c) AgRob V18 [28], (d) Forest robot 1 [29], (e) Forest robot 2 [30], (f) Superdroid [31] and (g) Husky A200 [32].

The AgRob V18 forest robot (Figure 5c) was developed to collect forest biomass [28]. The robot has a modular sensor tower, used to detect the fauna and flora around it. Because the locomotion system is of the Caterpillar type powered by a diesel engine, the IMU data are severely affected by the robot's vibration. For this reason, the researchers studied several approaches to perform autonomous robot localization and navigation, such as LOAM (recommended for structured environments), Advanced implementation of LOAM (A-LOAM) implemented in C++ to improve the speed of algorithm execution and Lightweight and Ground-Optimized LiDAR Odometry and Mapping (LeGO-LOAM). Among the three approaches, the SLAM technique that achieved the best performance was LeGO-LOAM [33].

According to Giusti et al. [34], an UAV (ARDrone) was used to perform visual-based navigation in a forest environment by extracting images from three different points of view (front and left and right side views) and using Deep Neural Networks (DNN) to classify the images received and estimate the direction of the trajectory to be followed. This type of application can assist in carrying out inventory operations, as described in [29]. Chen et al. [29] developed a UAV (Figure 5d) with an end-to-end pipeline for tree diameter estimation based on Semantic LOAM (S-LOAM), to increase robustness, scalability and performance in forest environments. The pipeline consists of: 3D point cloud labeling with virtual reality, range image segmentation with a Fully Convolutional Neural Network (FCNN), landmark instance detection with trellis graphs and S-LOAM [29]. When carrying out practical tests, the UAV was able to detect 29 trees (out of a total of 35) with an average error of $0.67 \mathrm{in}$.

Another method of estimating biomass in forest areas has been used in mangrove forests, in the northeast of Hainan Island, China [30]. In this case, Wang et al. [30] performed an estimate of above ground biomass using an upscaling method from field plots, UAV (Figure 5e) LiDAR data and Sentinel-2 imagery based on a point-line-polygon framework. 
Pierzchała et al. [31] used the Superdroid 4WD IG52 DB robot (Figure 5f) in a Norwegian forest, characterized by having a semi-structured flat terrain with little undergrowth. They used a 3D graph-SLAM approach, Random Sample Consensus (RANSAC), to identify the soil and Signed Distance (SD) to represent the standard height of measurements for the estimation of DBH. Due to the chosen environment (Figure 6a) having few obstacles, the proposed method obtained a mean estimation error of DHB of $2 \mathrm{~cm}$, and, for tree positioning accuracy, the mean error was $0.0476 \mathrm{~m}$.

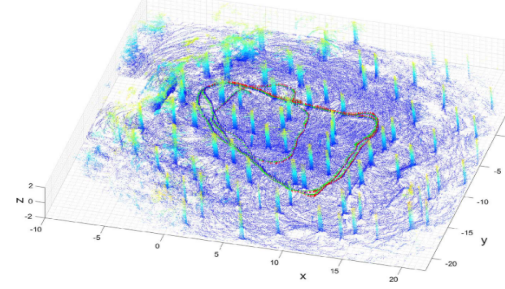

(a)

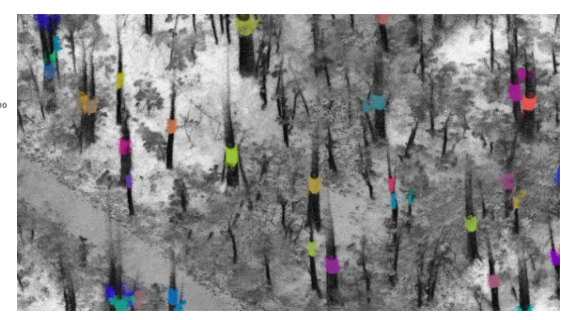

(b)

Figure 6. Tree detection during navigation activities: (a) results obtained by [31] and (b) results obtained by [32].

In a similar work, Tremblay et al. [32] analyzed several methods of automatic threedimensional mapping for tree diameter measurements in inventory operations. After considering a cylinder fitting for DBH estimation, different combinations of methods for determining circles were tested. All methods were combined using a median voting system. To evaluate the performance of the methods (Figure $6 \mathrm{~b}$ ), the researchers used the Clearpath Husky A200 robot (Figure 5g), containing a Velodyne LiDAR, an IMU, wheel encoders for odometry and a RGB camera. The robot was used in different types of forests (young, mixed, mature and maple) since each species of tree has a type of texture, which can directly affect the performance of DBH estimation. After performing several tests, the DBH estimation method that obtained the best performance was the vertical Axis + nonlinear least-squares cylinder, while Axis linear least-squares obtained the worst. The environment that obtained the best performance was mature, with well-spaced trees and visible trunks [32].

The Warthog robot, also from Clearpath, was used to move in subarctic and arctic environments based on the Iterative-Closest Point (ICP) algorithm. In an environment with snow and ice, due to its large moment of inertia, even after completing a curve, the robot remains slightly rotating. According to Baril et al. [35], for this type of scenario, angular displacement is the main characteristic that interferes with odometry systems. Thus, when performing inventory operations in environments with ice and snow, it is necessary to evaluate the kinematic model (ideal differential-drive, extended differentialdrive, radius-of-curvature-based and full linear) that best adapts to the type of terrain chosen [35].

In [36], a self-supervised detection method for forest land surfaces based on the Support Vector Machine (SVM) machine learning algorithm is implemented in the Pioneer 3-AT robot. Delaunay Triangulation was used to model the ground plane. Even under major changes in lighting and ground cover (with and without snow), the self-supervised learning method achieved an average accuracy of $81.46 \%$, while the method using morphological operators reached $95.21 \%$ and the classical supervised classifier obtained $74.27 \%$ [36]. This type of application may assist in reducing unwanted regions in the mapping activity of trees in forest inventory operations.

Table 3 summarizes the main characteristics of the robots mentioned above. 
Table 3. Comparison of the analyzed robotic applications for inventory operations.

\begin{tabular}{|c|c|c|c|}
\hline Robot & $\begin{array}{l}\text { Locomotion } \\
\text { System }\end{array}$ & Used Sensors & $\begin{array}{l}\text { Computer Vision } \\
\text { Algorithm }\end{array}$ \\
\hline FGI ROAMER R2 [27] & $4 \mathrm{WD}$ & GNSS, IMU, LiDAR & SLAM + IMU \\
\hline Komatsu Forest 931.1 [9] & $4 \mathrm{WD}$ & RTK GNSS, LiDAR & LOAM \\
\hline AgRob V18 [28] & Caterpillar & $\begin{array}{l}\text { GNSS, LiDAR, thermal } \\
\text { and RGB cameras }\end{array}$ & LeGO-LOAM \\
\hline ARDrone [34] & UAV & $\begin{array}{c}\text { RGB and grayscale } \\
\text { cameras }\end{array}$ & DNN \\
\hline Forest robot 1 [29] & UAV & LiDAR & SLOAM \\
\hline Forest robot $2[30]$ & UAV & LiDAR & G-LiDAR-S2 model \\
\hline Superdroid [31] & $4 \mathrm{WD}$ & $\begin{array}{l}\text { GPS, LiDAR, IMU } \\
\text { and stereo camera }\end{array}$ & 3D graph-SLAM \\
\hline Husky A200 [32] & $4 \mathrm{WD}$ & $\begin{array}{l}\text { LiDAR, IMU, encoders } \\
\text { and RGB camera }\end{array}$ & DBH estimation \\
\hline Warthog [35] & $4 \mathrm{WD}$ & $\begin{array}{l}\text { LiDAR, IMU and } \\
\text { encoders }\end{array}$ & ICP algorithm \\
\hline Pioneer 3-AT [36] & $4 \mathrm{WD}$ & XB3 camera and LiDAR & LIDAR/camera-based \\
\hline
\end{tabular}

Considering the information presented in Table 3, the following analysis can be done:

- Used Sensors: Although in forest environments the signals from GNSS devices are severely impaired, some applications use such devices, while in others the navigation was accomplished exclusively by LiDAR sensors.

- SLAM: Several types of SLAM were used since, although all applications are in forest environments, each type of forest (tropical, temperate), in each season and each type of soil can directly interfere with the navigation technique used. For example, the LOAM technique discarded by Reis et al. [28] was used by Li et al. [9] and obtained satisfactory results.

\subsection{Robotic Applications in Forest for Planting, Pruning and Harvesting}

To develop technological solutions that positively impact the environment, Birch and Rhodes [37] developed the TreeRover tree planter prototype, as depicted in Figure 7a. Guided by a GNSS system, the $4 \mathrm{WD}$ robot is capable of planting up to 10 tree seedlings. It has an exclusive system that pierces the earth, deposits the seedling with a compressed air system and finally covers the hole by pressing the local terrain [37].

The Multiscope Forester Planter (Figure 7b) is already a commercial planter robot, with a payload with a capacity of 380 seedlings. With a modular structure mounted on a Caterpillar system, the robot can reach up to $20 \mathrm{~km} / \mathrm{h}$, with a planting speed of $6.5 \mathrm{~h} / \mathrm{ha}$ in temperate forest environments and has two control systems: teleoperation or waypoint navigation [38]. Built on the same locomotion system as the Multiscope Forester Planter, the Multiscope Forester Brushcutter (Figure 7c) has a brush cutting tool and a hydraulic power unit, instead of the planting payload, to be used in forest mowing applications [39]. Due to the modular structure of both robots, both tasks can be performed during the execution of forestry activities. 


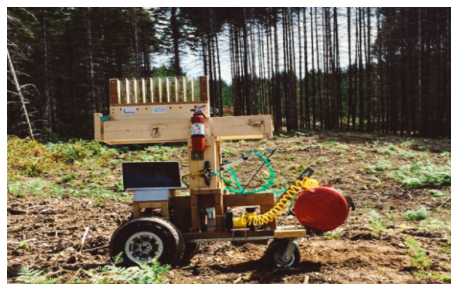

(a)

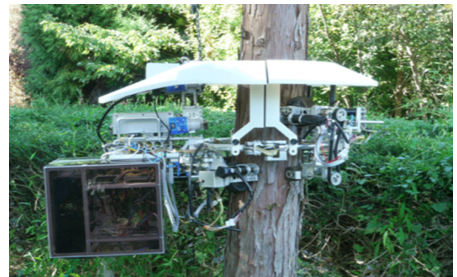

(d)

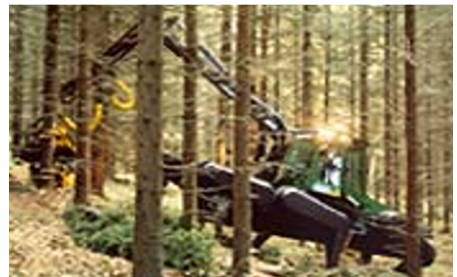

$(\mathrm{g})$

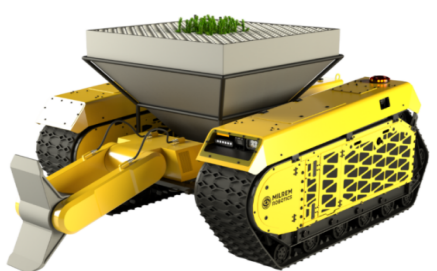

(b)

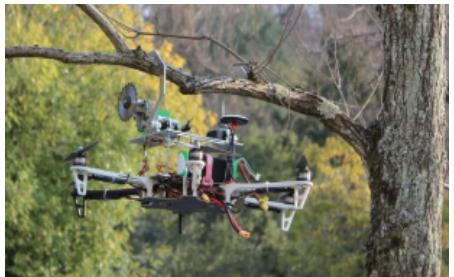

(e)

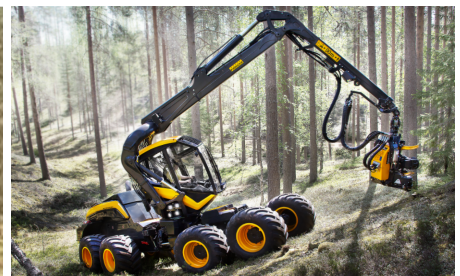

(h)

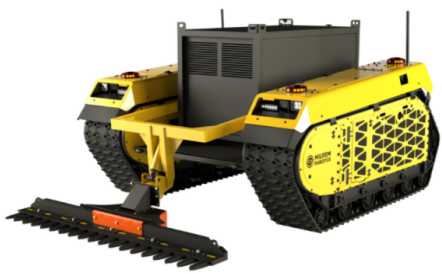

(c)

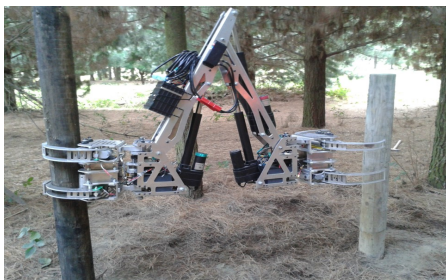

(f)

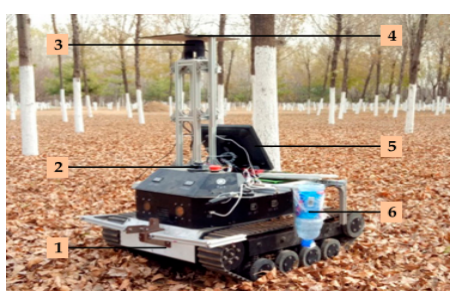

(i)

Figure 7. Examples of robotic applications used in forests for planting, pruning and harvesting tasks: (a) TreeRover [37], (b) Multiscope Forester Planter [38], (c) Multiscope Forester Brushcutter [39], (d) Pruning robot 1 [40], (e) Pruning robot 2 [41], (f) Pruning robot 3 [42], (g) Walking harvester [43], (h) Harvester CTL [44] and (i) Harvesting robot [45].

Robots used in tree pruning tasks must be able to climb trees, prune and descend. However, as described in [40], this task has several challenges, such as cutting the branches without letting the cutting tool be grabbed and pruning the tree without damaging the trunk, in addition to saving energy. To solve these problems, Ishigure et al. [40] developed a pruning robot (as shown climbing a tree in Figure 7d) with a movable bar mounted on the guide bar of the chainsaw so that it can move even if a branch is stuck in the chainsaw. To prevent the robot from damaging the tree trunk, it has a control system that always keeps the chainsaw parallel to the tree trunk. To save energy, the robot has a system for measuring the electric current consumed by the chainsaw; in this way, only when it detects a high consumption of electric current will it supply a higher voltage to the chainsaw, otherwise the voltage will remain low, resulting in a $34 \%$ reduction in energy consumption [40]. The pruning of trees located close to electric power transmission lines, unlike the aforementioned work, besides being dangerous, the way pruning depends on where the electric power transmission line is passing relative to the tree, that is, on the side, above or through the tree. In [41], the authors described a UAV that has a circular saw and two claws attached to its body so that, after flying to the position where the branch to be removed is, it hangs on the branch and performs a circular cutting movement around the branch (as shown hanging from a branch in Figures 7e and 8). The system, despite being in an initial testing phase, proved to be capable of pruning branches while being remotely controlled by a human [41]. 


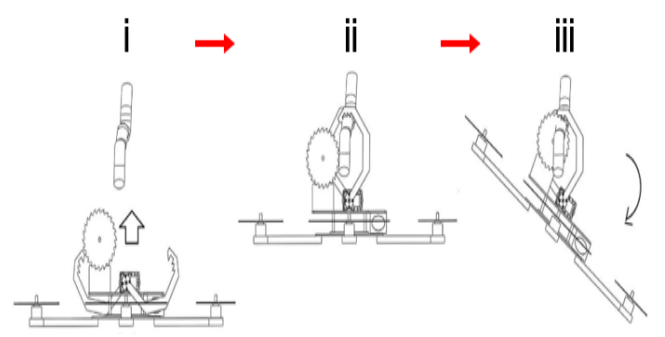

Figure 8. Circular saw, as described in detail in [41].

Unlike the types of locomotion commonly used in forests, the robot developed by Scion has a tree to tree locomotion system, using fixing claws (Figure 7f). The complete system has nine Degrees of Freedom (DoF) and can remain fixed only in one tree and move from one tree to the other with a minimum distance of $1 \mathrm{~m}$ and a maximum distance of $2.2 \mathrm{~m}$. The tree localization is done through the application of the Hough Transform (HT) under RGB images. The method was evaluated under different lighting conditions and it was still possible to detect the trunks. The system's path planning is based on the K-Means algorithm, which prioritizes the search for paths that visit a larger number of trees [42]. This type of robot was developed to perform tasks of measuring tree girth, location and mainly for pruning, as this locomotion system eliminates the need for a human to place/remove the pruning robot from the tree.

Developed in the 1990s, the fully independent hydraulic six-legged walking machine (MECANT robot) was one of the first legged robots built to be used in unstructured environments. Despite the technological limits of that time, MECANT was built using the off-the-shelf concept. Although the robot is guided by a human being, the architecture of the leg control system (3-DoF) and body position and orientation (6-DoF) is complex, separated into the following tasks: body path planner, gait planner, foothold planner, transfer and support trajectory planner and support force planner [46]. Legged robots do not need constant contact with the ground to get around and can adjust their posture according to the terrain slope [47]. This robot was the precursor to the walking forest harvester (Plustech Oy), illustrated in Figure 7g, which did not get a good acceptance from the forest machine market [43].

Unlike the walking forest harvester, the harvester machine based on the Cut-To-Length (CTL) method depicted in Figure 7h has wheels and performs log harvesting intelligently in boreal forest. The harvester CTL has a robotic arm that, in addition to slaughtering and stripping, measures the base and diameter of each harvested trunk and compares both with the averages of specific species and with the harvest history. Using an algorithm based on the data of each trunk, the harvester CTL optimizes each trunk to achieve the highest possible processing value. To reduce impacts on the environment, during harvesting, the CTL harvester covers its tracks with branches and tree debris to reduce damage to forest soil [44].

Even today, rubber extraction is considered a manual task. Using LiDAR sensors and low-cost gyroscopes, Zhang et al. [45] clustered the cloud of tree trunk points and extracted the central point of the trunks based on the Gauss-Newton method to create navigation lines for the robot itself to move around the environment using a Fuzzy control system. With this technique, the robotic platform (Figure 7i) moved by a caterpillar system obtained a Root Mean Square (RMS) side error less than $10.32 \mathrm{~cm}$, making it possible to carry out the rubber harvest in an automated way.

Table 4 summarizes the most relevant data for the robots mentioned above. 
Table 4. Comparison of the analyzed robotic applications in forest for planting, pruning and harvesting.

\begin{tabular}{|c|c|c|c|c|}
\hline $\begin{array}{c}\text { Final } \\
\text { Application }\end{array}$ & Robot & $\begin{array}{l}\text { Locomotion } \\
\text { System }\end{array}$ & Sensors & Actuators \\
\hline \multirow{3}{*}{ Planting } & TreeRover [37] & $4 \mathrm{WD}$ & GNSS & Compressed air machine \\
\hline & $\begin{array}{l}\text { Multiscope Forester } \\
\text { Planter [38] }\end{array}$ & Caterpillar & - & Forester planter \\
\hline & $\begin{array}{c}\text { Multiscope Forester } \\
\text { Brushcutter [39] }\end{array}$ & Caterpillar & - & Forester brushcutter \\
\hline \multirow{3}{*}{ Pruning } & Pruning robot 1 [40] & $4 \mathrm{WS}$ & Posture sensor & Chainsaw \\
\hline & Pruning robot 2 [41] & UAV & $\begin{array}{l}\text { Back-electromotive } \\
\text { force module }\end{array}$ & Circular saw \\
\hline & Pruning robot 3 [42] & Legged robot & $\begin{array}{l}\text { LiDAR and } \\
\text { RGB camera }\end{array}$ & - \\
\hline \multirow{4}{*}{ Harvesting } & MECANT [46] & Legged robot & - & - \\
\hline & $\begin{array}{l}\text { Walking forest } \\
\text { harvester [43] }\end{array}$ & Legged robot & - & $\begin{array}{l}\text { Chainsaw on a robotic } \\
\text { arm }\end{array}$ \\
\hline & Harvester CTL [44] & Legged robot & - & $\begin{array}{l}\text { Chainsaw on a robotic } \\
\text { arm }\end{array}$ \\
\hline & Harvesting robot [45] & Caterpillar & $\begin{array}{l}\text { LiDAR and } \\
\text { gyroscope }\end{array}$ & Gauss-Newton \\
\hline
\end{tabular}

Regarding the information presented in Table 4, the following observations can be made:

- Used Sensors: As most applications were teleoperated, few sensors were used and, therefore, this strategy enhances cost reduction.

- Used Actuators: Different reasons for pruning result in different locomotion and cutting systems. Thus, periodic pruning tasks were performed using UAV (with mini saws), whereas daily log harvesting tasks were performed by legged robots (with chain saws).

- Locomotion Systems: The reasons for using certain types of locomotion must not only be well defined, but they must also exhibit results that satisfy the forest machine market.

\section{Discussion}

As done for the work related to the development of robotic systems applied in agricultural environments [48], the collection of several data in common for the different types of robotic systems applications in forest environments was carried out, the results of which are shown in Figure 9. 


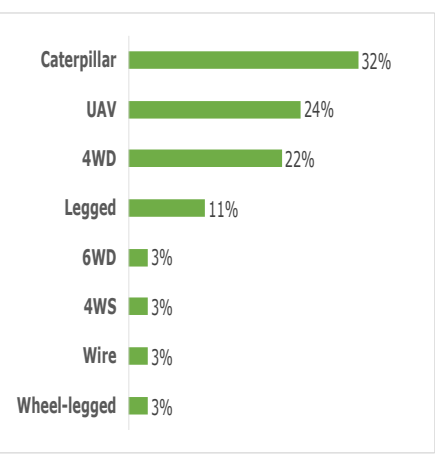

(a)Locomotion System.

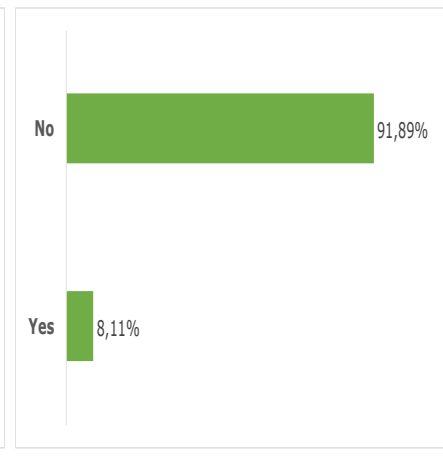

(b)Robotic Arm.

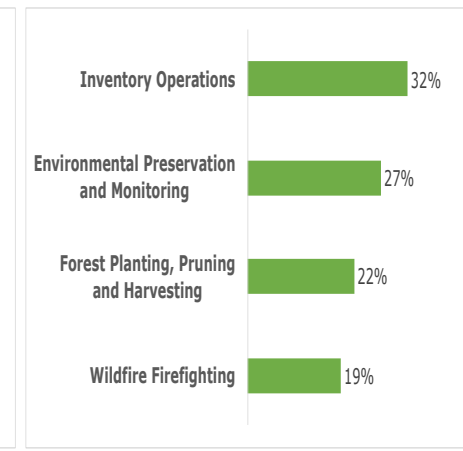

(c)Final Application.

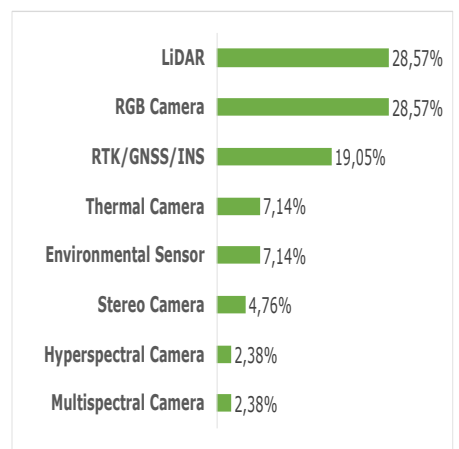

(d)Sensors.

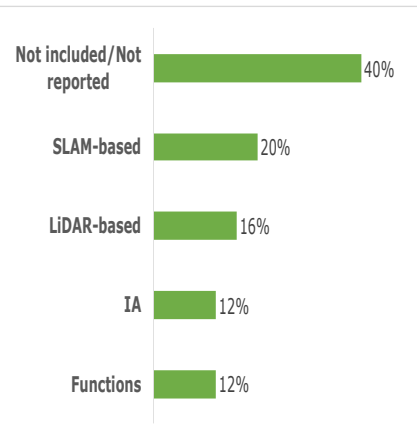

(e)Computer Vision Algorithm.

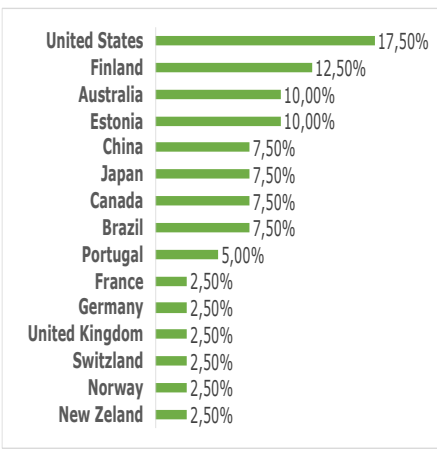

(f)Country.

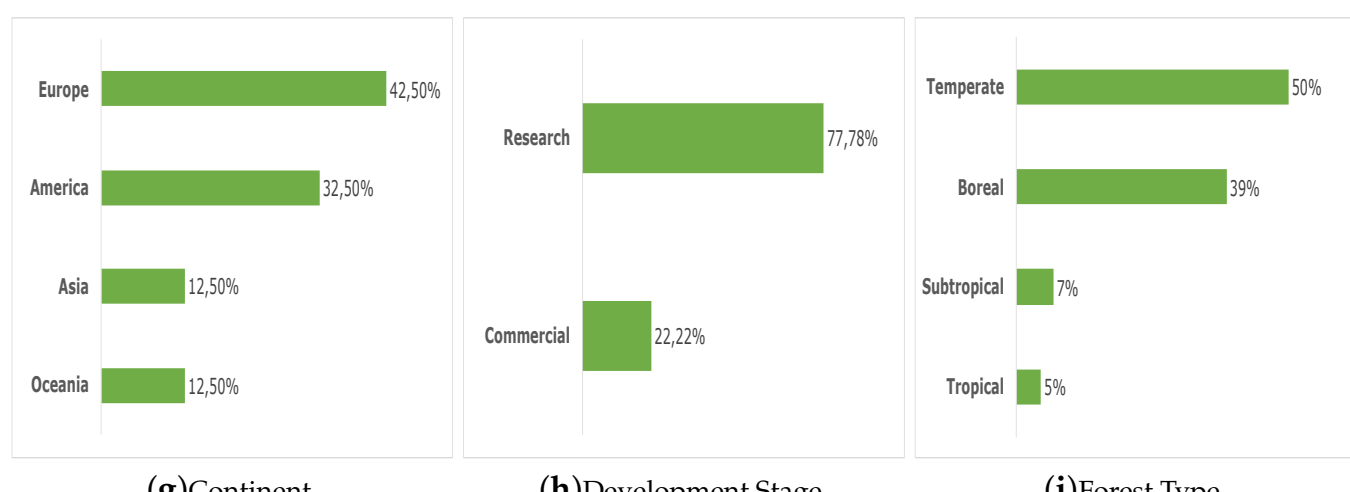

(g)Continent.

(h)Development Stage.

(i)Forest Type.

Figure 9. Summary of analyzed forest robots' characteristics.

After analyzing the various graphs shown in Figure 9, the data reveal that most of the forest robots analyzed have caterpillars (Figure 9a), do not have robotic arms (Figure 9b) and are related to the execution of inventory operations (Figure 9c). Although most robots use LiDAR and RGB cameras (28.57\%, according to Figure $9 \mathrm{~d})$, most of the studies $(40 \%$, according to Figure 9e) do not include or report computer vision algorithms. The data also reveal that most robotic systems developed to perform forestry tasks of environmental preservation, monitoring, wildfire firefighting, inventory operations, planting, pruning and harvesting were developed by companies/researchers from the United States $(17.50 \%$, as shown in Figure 9f); however, $42.50 \%$ of all work was carried out in countries on the European continent and $77.78 \%$ are still in the research phase, as shown in Figure $9 \mathrm{~g}, \mathrm{~h}$, respectively. Among the reviewed works, the United States was the country that stood out, with $17.50 \%$ of the total analyzed works. To understand the reason, the FAO data were analyzed [49]. In this case, the percentage of the total forest area of each country involved with the articles/companies/projects reviewed is depicted in Figure 10. 
Forest Land Area

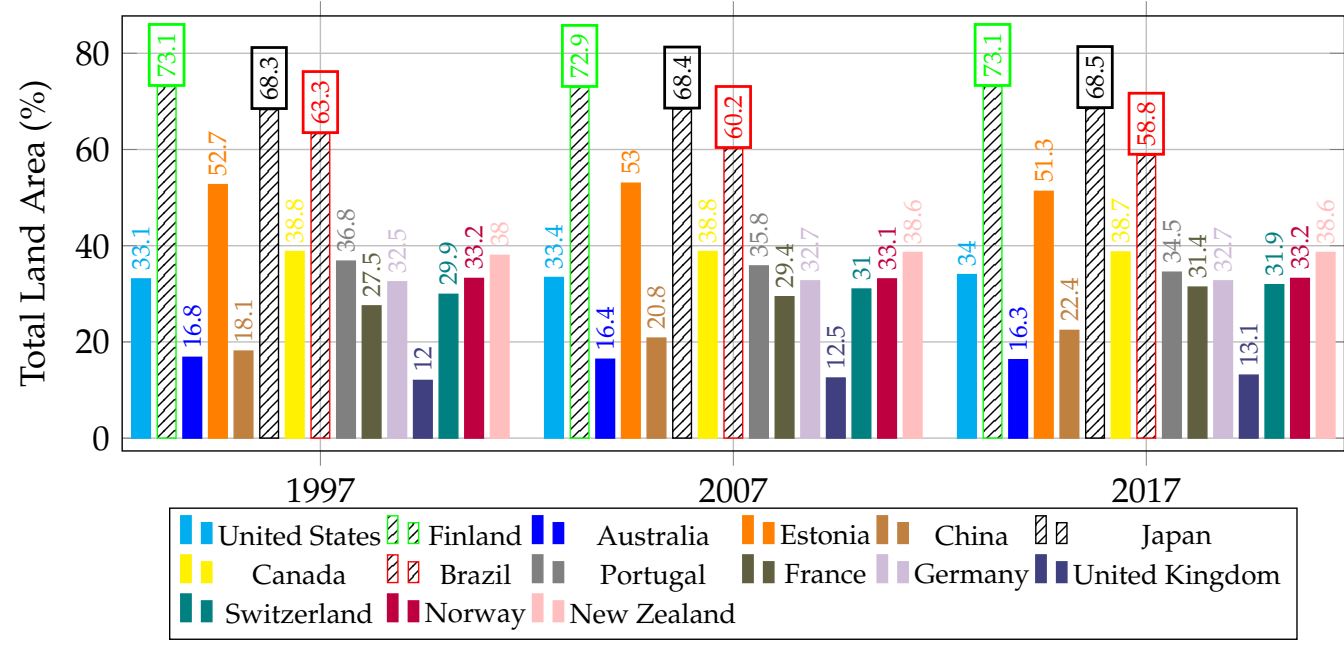

Figure 10. Total forest area of all countries related to the development of robotic forest systems covered in this article, according to FAO data [49].

According to Figure 10, Finland, Japan and Brazil are the three countries with the highest percentages of total forest area, in relation to the reviewed works. During the twenty years of monitoring (1997-2017), Finland maintained the same preservation values, while Brazil presented a reduction of $7.11 \%$ in forest area. However, $58.8 \%$ of $8,358,140 \mathrm{~km}^{2}$ (land area of Brazil) is equivalent to $4,914,586.32 \mathrm{~km}^{2}$ and $73.1 \%$ of $303,910 \mathrm{~km}^{2}$ (land area of Finland) is equivalent to $222,158.21 \mathrm{~km}^{2}$, that is, the forest land area of Brazil is about 22.12 times larger than the forest land area of Finland [50]. In this sense, despite the remote sensing carried out by satellites being able to monitor large forest areas, it is not able to act directly in the fight against illegal logging and forest fires. Thus, the great importance of investing in mobile, robust and agile robotic systems, capable of sensing and acting under the surrounding environment and remotely communicating with other robots, is noted, contributing to better preservation of extensive forest areas. Based on FAO [1], the reviewed papers are distributed in four types of forest zones: boreal, temperate, subtropical and tropical. As shown in Figure $9 \mathrm{i}$, about $50 \%$ of the works were applied to temperate forest zones and, due to the little documentation found of works developed in the African continent, as well as in the other countries of Oceania and Latin America, only $5 \%$ of the works were applied in tropical zones.

\subsection{Unsolved Issues}

After analyzing the various existing works, as described above, to improve the precision and time of execution of the several robotic applications in forest for environmental preservation, monitoring, wildfire firefighting, inventory operations, planting, pruning and harvesting, in the authors' opinion two main areas need improvements: IoT-based smart forest and navigation systems.

\subsubsection{IoT-Based Smart Forest}

A characteristic commonly observed when analyzing the works $[14,15,18,19]$ is the ability to use wireless communication technologies to exchange information between different robotic systems (aerial and terrestrial robots) and smart devices, sensors that detect the forest fires and monitor the quality of air, soil, water and vegetation indexes. In this sense, it is proposed as a future research work to integrate intelligent sensors (temperature, humidity, gas and luminosity) with forest robotic systems, since through the fusion of such technologies it will be possible to carry out forest preservation and monitoring activities of large portions of Earth with high spatial and temporal resolution. Since a forest is an unstructured environment, the concept of the swarm of robots needs to 
be applied not only in UAV but also in other locomotion systems to enable the execution of forestry tasks, such as planting, pruning and harvesting, in a faster and more efficient way to reduce environmental damage.

\subsubsection{Navigation Systems}

The most recurrent problem with mobile robot applications in forest environments is that of the navigation system [51-53]. In this sense, several SLAM techniques have been used, such as SLAM + IMU [27], LOAM [9], A-LOAM [28], LeGO-LOAM [33], S-LOAM [29] and 3D graph-SLAM [31]. Thus, future research must assess the proposed systems' complexity to ensure that the trade offs between low-cost and high precision and between simplicity and efficiency have the results necessary to carry out their respective activities, contributing to the improvement of localization and navigation tasks. Another proposal for improving navigation systems would be to use Ground Penetration Radar (GPR) type sensors $[28,54]$ together with the use of artificial intelligence algorithms. GPR sensors map the soil at different depth levels, revealing the contents of the subsoil. In this way, a computer vision system using GPR would eliminate all problems of variation of natural lighting and interference of the seasons, as in this case the system would be analyzing the soil in search of natural landmarks, as a way of locating and navigating along the plantation.

\section{Conclusions}

The development of robotic systems to operate in forest environments is of great relevance for the public (preservation of fauna and flora) and private (income generation) sectors. In this sense, this article reviews several scientific articles, research projects and commercial products related to robotic applications for environmental preservation, monitoring, wildfire firefighting, inventory operations, planting, pruning and harvesting. After conducting a critical analysis, it was observed that: $32 \%$ of the robots have caterpillars, $91.89 \%$ do not have robotic arms, $32 \%$ of the works address the use of robots in inventory operations, $28.57 \%$ use LiDAR and RGB cameras, $40 \%$ do not include or report computer vision algorithms, $17.50 \%$ were developed by companies/researchers from the United States, $77.78 \%$ remain in the research phase, $42.50 \%$ were carried out on the European continent and $50 \%$ were applied in temperate forests. The main characteristics observed were: (a) the locomotion system is directly affected by the type of environmental monitoring to be performed; (b) different reasons for pruning result in different locomotion and cutting systems; (c) each type of forest (tropical or temperate), in each season and each type of soil can directly interfere with the navigation technique used; and (d) the integration of the concept of swarm of robots with robots of different types of locomotion systems (land, air or sea) can compensate for the time of executing tasks in unstructured environments. Two major areas are proposed by the paper authors for future research works: IoT-based smart forest and navigation systems. In addition, due to the existence of few studies developed in tropical forest areas, it is proposed to develop future research works in tropical regions, such as those found in Latin America and on the African and Oceania continents. Therefore, it is expected that, with the various characteristics exposed in this article, the current robotic forest systems are improved, so that forest exploitation becomes more efficient and sustainable.

Author Contributions: Conceptualization, M.F.S. and A.P.M.; Methodology, L.F.P.O. and M.F.S.; Investigation, L.F.P.O., M.F.S. and A.P.M.; Writing-Original Draft Preparation, L.F.P.O., M.F.S. and A.P.M.; Writing-Review and Editing, L.F.P.O., M.F.S. and A.P.M.; Visualization, L.F.P.O. and M.F.S.; Supervision, M.F.S. and A.P.M.; and Project Administration, M.F.S. and A.P.M. All authors have read and agreed to the published version of the manuscript.

Funding: This work was financed by National Funds through the Portuguese funding agency, FCT-Fundação para a Ciência e a Tecnologia, within project UIDB/50014/2020.

Institutional Review Board Statement: Not applicable. 
Informed Consent Statement: Not applicable.

Data Availability Statement: Not applicable.

Acknowledgments: The authors would like to thank the following individuals and institutions for giving permission to reprint the figures and photographs presented in this paper: Figure 2a: Ney Robinson Salvi dos Reis (Research and Development Center (CENPES) of Petrobras S.A.); Figure 2b: Ryan James Steindl (Robotics and Autonomous Systems Group of Commonwealth Scientific and Industrial Research Organisation (CSIRO)); Figure 2c: Yousef Emam (Georgia Institute of Technology); Figure 2d: Micael Couceiro (Institute of Systems and Robotics of University of Coimbra (ISR-UC)); Figure 2e: Nathan Melenbrink (School of Engineering and Applied Sciences of Harvard University); Figure 2f: Juan Sandino (permission granted under Creative Commons CC BY 4.0 licence terms); Figure 2g: Takanori Matsui (permission granted under Creative Commons CC BY 4.0 licence terms); Figure 2h: André Farinha (permission granted under Creative Commons CC BY 4.0 licence terms); Figure 2i: Pauline Pounds (University of Queensland); Figures 2j and 3a,b: Felipe Gonzalez (permission granted under Creative Commons CC BY 4.0 licence terms); Figures $4 \mathrm{a}, \mathrm{b}$, and 7b,c: Gert Hankewitz (Milrem Robotics); Figure 4c: Manon Vermenouze (Shark Robotics); Figure 5a: Yuwei Chen (permission granted under Creative Commons CC BY 4.0 licence terms); Figure 5b: Qingqing $\mathrm{Li}$ (permission granted under Creative Commons CC BY 4.0 licence terms); Figure 5c: Filipe Neves Dos Santos (Centre for Robotics in Industry and Intelligent Systems - CRIIS INESC TEC); Figure 5d: Guilherme Nardari (Robot Learning Laboratory of University of São Paulo); Figure 5e: Bo Wan (permission granted under Creative Commons CC BY-NC-ND 4.0 licence terms); Figures $5 \mathrm{f}$ and 6a: Marek Pierzchała (permission granted under Creative Commons CC BY-NC-ND 4.0 licence terms); Figures 5g and 6b: Jean-François Tremblay (Mobile robotics laboratory, McGill University); Figure 7a: Nick Birch (Iotatel Inc.); Figure 7d: Haruhisa Kawasaki (Gifu University); Figures 7e and 8: Javier Molina (permission granted under Creative Commons CC BY 4.0 licence terms); Figure 7f: Richard Parker (Scion Research); Figure 7g: Aarne Halme (Department of Electrical Engineering and Automation of Aalto University); Figure 7h: Éllen Bianchi (Ponsse Plc); and Figure 7i: Ying Chen (permission granted under Creative Commons CC BY 4.0 licence terms).

Conflicts of Interest: The authors declare no conflict of interest.

\section{References}

1. FAO. The State of the World's Forests 2020. Forests, Biodiversity and People; FAO: Rome, Italy, 2020; p. 214. [CrossRef]

2. FAO. The State of the World's Forests 2018. Forest Pathways to Sustainable Development; FAO: Rome, Italy, $2018 ;$ p. 139.

3. Paiva, P.F.P.R.; Ruivo, M.d.L.P.; Júnior, O.M.d.S.; Maciel, M.d.N.M.; Braga, T.G.M.; de Andrade, M.M.N.; dos Santos Junior, P.C.; da Rocha, E.S.; de Freitas, T.P.M.; Leite, T.V.d.S.; et al. Deforestation in protect areas in the Amazon: A threat to biodiversity. Biodivers. Conserv. 2020, 29, 19-38. [CrossRef]

4. Boer, M.M.; Dios, V.R.; Bradstock, R.A. Unprecedented burn area of Australian mega forest fires. Nat. Clim. Chang. 2020, 10, 171-172. [CrossRef]

5. Spaniol, R.L.; Mendonça, M.d.S.; Hartz, S.M.; Iserhard, C.A.; Stevens, M. Discolouring the Amazon Rainforest: How deforestation is affecting butterfly coloration. Biodivers. Conserv. 2020, 29, 2821-2838. [CrossRef]

6. CRED. Economic, Losses, Poverty E Disasters: 1998-2017; CRED: Bengaluru, India, 2018; p. 33.

7. Oliveira, L.F.P.; Manera, L.T.; Luz, P.D.G. Smart Traffic Light Controller System. In Proceedings of the 2019 Sixth International Conference on Internet of Things: Systems, Management and Security (IOTSMS), Granada, Spain, 22-25 October 2019; pp. 155-160. [CrossRef]

8. Oliveira, L.F.P.; Manera, L.T.; Luz, P.D.G. Development of a Smart Traffic Light Control System with Real-Time Monitoring. IEEE Internet Things J. 2020, 8, 3384-3393. [CrossRef]

9. Li, Q.; Nevalainen, P.; Queralta, J.P.; Heikkonen, J.; Westerlund, T. Localization in Unstructured Environments: Towards Autonomous Robots in Forests with Delaunay Triangulation. Remote Sens. 2020, 12, 1870. [CrossRef]

10. Freitas, G.; Gleizer, G.; Lizarralde, F.; Hsu, L.; Reis, N.R.S. Kinematic reconfigurability control for an environmental mobile robot operating in the Amazon rain forest. J. Field Robot. 2010, 27, 197-216. [CrossRef]

11. Reis, N.R.S. Desenvolvimento de tecnologias como conjunto de ferramentas e suporte às atividades e pesquisas socioambientais na Amazônia brasileira: Mobilidade e acessibilidade em áreas de várzea. Master's Thesis, Universidade Federal do Amazonas, Manaus, Amazonas, Brazil, 2010.

12. CSIRO. Amazon 360: Testing Self-Navigation in a Novel Landscape. 2020. Available online: https://algorithm.data61.csiro.au/ amazon-360-testing-self-navigation-in-a-novel-landscape/ (accessed on 8 March 2021).

13. Notomista, G.; Emam, Y.; Egerstedt, M. The SlothBot: A Novel Design for a Wire-Traversing Robot. IEEE Robot. Autom. Lett. 2019, 4, 1993-1998. [CrossRef] 
14. Couceiro, M.S.; Portugal, D.; Ferreira, J.F.; Rocha, R.P. SEMFIRE: Towards a new generation of forestry maintenance multirobot systems. In Proceedings of the 2019 IEEE/SICE International Symposium on System Integration (SII), Paris, France, 14-16 January 2019; pp. 270-276.

15. Melenbrink, N.; Werfel, J. Autonomous Sheet Pile Driving Robots for Soil Stabilization. In Proceedings of the 2019 International Conference on Robotics and Automation (ICRA), Montreal, QC, Canada, 20-24 May 2019; pp. 339-345.

16. Sandino, J.; Pegg, G.; Gonzalez, F.; Smith, G. Aerial Mapping of Forests Affected by Pathogens Using UAVs, Hyperspectral Sensors, and Artificial Intelligence. Sensors 2018, 18, 944. [CrossRef]

17. Fujimoto, A.; Haga, C.; Matsui, T.; Machimura, T.; Hayashi, K.; Sugita, S.; Takagi, H. An End to End Process Development for UAV-SfM Based Forest Monitoring: Individual Tree Detection, Species Classification and Carbon Dynamics Simulation. Forests 2019, 10, 680. [CrossRef]

18. Farinha, A.; Zufferey, R.; Zheng, P.; Armanini, S.F.; Kovac, M. Unmanned Aerial Sensor Placement for Cluttered Environments. IEEE Robot. Autom. Lett. 2020, 5, 6623-6630. [CrossRef]

19. Pounds, P.; Singh, S. Samara: Biologically Inspired Self-Deploying Sensor Networks. IEEE Potentials 2015, 34, 10-14. [CrossRef]

20. Gonzalez, L.F.; Montes, G.A.; Puig, E.; Johnson, S.; Mengersen, K.; Gaston, K.J. Unmanned Aerial Vehicles (UAVs) and Artificial Intelligence Revolutionizing Wildlife Monitoring and Conservation. Sensors 2016, 16, 97. [CrossRef] [PubMed]

21. Apparatus, F. Firefighting Robotic Vehicle System. 2020. Available online: https://www.fireapparatusmagazine.com/fireapparatus / firefighting-robotic-vehicle-system/\#gref (accessed on 9 March 2021).

22. Milrem Robotics. Multiscope Rescue with Hydra. 2020. Available online: https://milremrobotics.com/product/multiscoperescue-hydra/ (accessed on 9 March 2021).

23. Milrem Robotics. Multiscope Rescue Hose Cartridge. 2020. Available online: https://milremrobotics.com/product/firehousecontainer / (accessed on 9 March 2021).

24. Shark Robotics. Colossus. 2020. Available online: https://www.shark-robotics.com/shark-robots (accessed on 10 March 2021).

25. Magirus. Magirus AirCore. 2020. Available online: https://www.magirusgroup.com/de/en/products/special-vehicles/aircore/ (accessed on 10 March 2021).

26. Howe \& Howe. Thermite-First Commercial Firefighting Robot Sold in the U.S. 2020. Available online: https://www. howeandhowe.com/civil/thermite (accessed on 10 March 2021).

27. Tang, J.; Chen, Y.; Kukko, A.; Kaartinen, H.; Jaakkola, A.; Khoramshahi, E.; Hakala, T.; Hyyppä, J.; Holopainen, M.; Hyyppä, H. SLAM-Aided Stem Mapping for Forest Inventory with Small-Footprint Mobile LiDAR. Forests 2015, 6, 4588-4606. [CrossRef]

28. Reis, R.; Santos, F.N.S.; Santos, L. Forest Robot and Datasets for Biomass Collection. In Robot 2019: Fourth Iberian Robotics Conference; Springer: Berlin/Heidelberg, Germany, 2020; pp. 152-163. [CrossRef]

29. Chen, S.W.; Nardari, G.V.; Lee, E.S.; Qu, C.; Liu, X.; Romero, R.A.F.; Kumar, V. SLOAM: Semantic Lidar Odometry and Mapping for Forest Inventory. IEEE Robot. Autom. Lett. 2020, 5, 612-619. [CrossRef]

30. Wang, D.; Wan, B.; Liu, J.; Su, Y.; Guo, Q.; Qiu, P.; Wu, X. Estimating aboveground biomass of the mangrove forests on northeast Hainan Island in China using an upscaling method from field plots, UAV-LiDAR data and Sentinel-2 imagery. Int. J. Appl. Earth Obs. Geoinf. 2020, 85, 101986. [CrossRef]

31. Pierzchała, M.; Giguère, P.; Astrup, R. Mapping forests using an unmanned ground vehicle with 3D LiDAR and graph-SLAM. Comput. Electron. Agric. 2018, 145, 217-225. [CrossRef]

32. Tremblay, J.F.; Béland, M.; Gagnon, R.; Pomerleau, F.; Giguère, P. Automatic three-dimensional mapping for tree diameter measurements in inventory operations. J. Field Robot. 2020, 37, 1328-1346. [CrossRef]

33. Shan, T.; Englot, B. LeGO-LOAM: Lightweight and Ground-Optimized Lidar Odometry and Mapping on Variable Terrain. In Proceedings of the 2018 IEEE/RSJ International Conference on Intelligent Robots and Systems (IROS), Madrid, Spain, 1-5 October 2018; pp. 4758-4765. [CrossRef]

34. Giusti, A.; Guzzi, J.; Cireşan, D.C.; He, F.; Rodríguez, J.P.; Fontana, F.; Faessler, M.; Forster, C.; Schmidhuber, J.; Caro, G.D.; et al. A Machine Learning Approach to Visual Perception of Forest Trails for Mobile Robots. IEEE Robot. Autom. Lett. 2016, 1, 661-667. [CrossRef]

35. Baril, D.; Grondin, V.; Deschênes, S.; Laconte, J.; Vaidis, M.; Kubelka, V.; Gallant, A.; Giguère, P.; Pomerleau, F. Evaluation of Skid-Steering Kinematic Models for Subarctic Environments. In Proceedings of the 202017 th Conference on Computer and Robot Vision (CRV), Ottawa, ON, Canada, 13-15 May 2020; pp. 198-205. [CrossRef]

36. Zhou, S.; Xi, J.; McDaniel, M.W.; Nishihata, T.; Salesses, P.; Iagnemma, K. Self-supervised learning to visually detect terrain surfaces for autonomous robots operating in forested terrain. J. Field Robot. 2012, 29, 277-297. [CrossRef]

37. Birch, N.; Rhodes, T. Engineering co-op Students Build Tree-Planting Robot to Help Fight Deforestation. 2016. Available online: https: / / www.uvic.ca/news/topics/2016+building-a-tree-planting-robot+ring (accessed on 11 March 2021).

38. Milrem Robotics. Multiscope Forester Planter. 2020. Available online: https://milremrobotics.com/product/robotic-foresterplanter/ (accessed on 11 March 2021).

39. Milrem Robotics. Multiscope Forester Brushcutter. 2020. Available online: https://milremrobotics.com/product/roboticforester-brushcutter/ (accessed on 11 March 2021).

40. Ishigure, Y.; Hirai, K.; Kawasaki, H. A pruning robot with a power-saving chainsaw drive. In Proceedings of the 2013 IEEE International Conference on Mechatronics and Automation, Takamatsu, Japan, 4-7 August 2013; pp. 1223-1228. [CrossRef]

41. Molina, J.; Hirai, S. Aerial pruning mechanism, initial real environment test. Robot. Biomim. 2017, 4, 15. [CrossRef] [PubMed] 
42. Meaclem, C.V.; Shao, L.; Parker, R.; Gutschmidt, S.; Hann, C.E.; Milne, B.J.E.; Chen, X. Sensor guided biped felling machine for steep terrain harvesting. In Proceedings of the 2014 IEEE International Conference on Automation Science and Engineering (CASE), New Taipei, Taiwan, 18-22 August 2014; pp. 984-989. [CrossRef]

43. Billingsley, J.; Visala, A.; Dunn, M. Robotics in Agriculture and Forestry. In Springer Handbook of Robotics; Springer Berlin Heidelberg: Berlin/Heidelberg, Germany, 2008; pp. 1065-1077. [CrossRef]

44. Ponsse. The Cut-To-Length Method. 2020. Available online: https://www.ponsse.com/cut-to-length\#/ (accessed on 12 March 2021).

45. Zhang, C.; Yong, L.; Chen, Y.; Zhang, S.; Ge, L.; Wang, S.; Li, W. A Rubber-Tapping Robot Forest Navigation and Information Collection System Based on 2D LiDAR and a Gyroscope. Sensors 2019, 19, 2136. [CrossRef] [PubMed]

46. Halme, A.; Hartikainen, K.; Kärkkäinen, K. Terrain Adaptive Motion and Free Gait of a Six-Legged Walking Machine. IFAC Proc. Vol. 1993, 26, 1-7. [CrossRef]

47. Oliveira, L.F.P.; Rossini, F.L. Modeling, Simulation and Analysis of Locomotion Patterns for Hexapod Robots. IEEE Latin Am. Trans. 2018, 16, 375-383. [CrossRef]

48. Oliveira, L.F.P.; Silva, M.F.; Moreira, A.P. Agricultural Robotics: A State of the Art Survey. In 23rd International Conference on Climbing and Walking Robots and the Support Technologies for Mobile Machines (CLAWAR 2020); Gradetsky, V., Tokhi, M., Bolotnik, N., Silva, M., Virk, G., Eds.; CLAWAR Association Ltd.: High Wycombe, UK, 2020; pp. 279-286. [CrossRef]

49. FAO. World Food and Agriculture-Statistical pocketbook 2019; FAO: Rome, Italy, 2019; p. 254.

50. World Bank Group. Land Area. 2020. Available online: https://data.worldbank.org/indicator/AG.LND.TOTL.K2?name_desc= false (accessed on 12 March 2021).

51. Iqbal, J.; Xu, R.; Sun, S.; Li, C. Simulation of an Autonomous Mobile Robot for LiDAR-Based In-Field Phenotyping and Navigation. Robotics 2020, 9, 46. [CrossRef]

52. Aguiar, A.S.; Santos, F.N.; Cunha, J.B.; Sobreira, H.; Sousa, A.J. Localization and Mapping for Robots in Agriculture and Forestry: A Survey. Robotics 2020, 9, 97. [CrossRef]

53. Santos, L.C.; Aguiar, A.S.; Santos, F.N.; Valente, A.; Petry, M. Occupancy Grid and Topological Maps Extraction from Satellite Images for Path Planning in Agricultural Robots. Robotics 2020, 9, 77. [CrossRef]

54. Lever, J.H.; Delaney, A.J.; Ray, L.E.; Trautmann, E.; Barna, L.A.; Burzynski, A.M. Autonomous GPR Surveys using the Polar Rover Yeti. J. Field Robot. 2013, 30, 194-215. [CrossRef] 